\title{
Drizzle formation in stratocumulus clouds: effects of turbulent mixing
}

\author{
L. Magaritz-Ronen, M. Pinsky, and A. Khain \\ Department of Atmospheric Sciences, The Hebrew University of Jerusalem, Israel \\ Correspondence to: L. Magaritz-Ronen (leehi.magaritz@mail.huji.ac.il)
}

Received: 5 August 2015 - Published in Atmos. Chem. Phys. Discuss.: 7 September 2015

Revised: 11 January 2016 - Accepted: 28 January 2016 - Published: 17 February 2016

\begin{abstract}
The mechanism of drizzle formation in shallow stratocumulus clouds and the effect of turbulent mixing on this process are investigated. A Lagrangian-Eularian model of the cloud-topped boundary layer is used to simulate the cloud measured during flight RF07 of the DYCOMS-II field experiment. The model contains $\sim 2000$ air parcels that are advected in a turbulence-like velocity field. In the model all microphysical processes are described for each Lagrangian air volume, and turbulent mixing between the parcels is also taken into account. It was found that the first large drops form in air volumes that are closest to adiabatic and characterized by high humidity, extended residence near cloud top, and maximum values of liquid water content, allowing the formation of drops as a result of efficient collisions. The first large drops form near cloud top and initiate drizzle formation in the cloud. Drizzle is developed only when turbulent mixing of parcels is included in the model. Without mixing, the cloud structure is extremely inhomogeneous and the few large drops that do form in the cloud evaporate during their sedimentation. It was found that turbulent mixing can delay the process of drizzle initiation but is essential for the further development of drizzle in the cloud.
\end{abstract}

\section{Introduction}

Understanding the mechanism of drizzle formation in stratocumulus clouds $(\mathrm{Sc})$ is a long-standing problem in cloud physics. Formation of drizzle in the cloud leads to changes in the radiative properties of Sc (Nakajima and King, 1990; Gerber, 1996; Feingold et al., 1999; Brenguier et al., 2000; Rosenfeld et al., 2006, 2012). Sc cover large areas of the globe and as a result microphysical processes occurring within them have a profound effect on global radiation balance. The problem of drizzle formation is also interesting from a theoretical point of view. In Sc, drizzle forms within narrow cloud layers of a few hundred meters, which contain only little liquid water compared to more developed cumulus. Studies have shown that both an increase in cloud depth (Pawlowska and Brenguier, 2003; Kostinski, 2008) and an increase in the drop residential time in the cloud (Feingold et al., 1996; Magaritz et al., 2009) foster drizzle formation.

Warm Sc were investigated numerically using Large Eddy Simulations (LES) with different levels of complexity to describe microphysical processes (Stevens et al., 2003b, 2005; Ackerman et al., 2009). Among these, LES models of Sc with spectral bin microphysics were used to parameterize the rates of auto-conversion and drizzle formation (Khairoutdinov and Kogan, 1999). These parameterizations are widely used in large-scale models (Randall et al., 2003). And still, many LES models fail to reproduce the observed structure of Sc. Specifically, LES tend to substantially underestimate values of liquid water content (LWC) near cloud top (Stevens et al., 2005). Stevens et al. (2005) attributed these results to uncertainties in the description of small-scale turbulent motion in LES models. That study concluded that a realistic structure of Sc can be simulated only if the LES has a spatial resolution as low as $1 \mathrm{~m}$ - i.e., in configurations in which most turbulent motions are described explicitly.

Pinsky et al. (2008) and Magaritz et al. (2009) described a new Sc model, referred to as a Lagrangian-Eulerian model (LEM). In the model several thousand adjacent parcels (Lagrangian) move within a turbulence-like flow, with statistical parameters measured in the Stratocumulus-Topped Boundary Layer (STBL). The initial model version (Pinsky et al., 2008; Magaritz et al., 2009) did not include turbulent mixing 
of adjacent parcels and did not consider the effects of mixing and entrainment at the upper cloud boundary. Nonetheless, the model successfully simulated many observed properties, such as LWC, droplet size distribution, and drizzle formation. It was found that drizzle forms initially in "lucky" parcels that ascend from the ocean surface and spend the most time near cloud top. Such lucky parcels were estimated to comprise about $1 \%$ of all air parcels. The large droplets falling from "lucky" parcels trigger collisions and drizzle formation in parcels located below them. It was found that drizzle tends to fall in downdrafts created by large eddies in the STBL.

In the previous model version, consideration of a more realistic STBL geometry, characterized by a dry and warm inversion layer above the cloud top, led to the formation of an unrealistic cloud structure. The extremely inhomogeneous structure was caused by entrainment of dry and warm air volumes into the cloud layer. The radius of correlation of all microphysical variables became equal to parcel size selected in the model, which is much lower than the radii of correlation calculated from observed data.

In order to make cloud structure realistic and represent processes resulting from interaction with the inversion layer, it was necessary to take into account processes of entrainment and mixing of adjacent parcels (Magaritz-Ronen et al., 2014). It was shown that turbulent mixing of parcels leads to realistic spatial variability of microphysical quantities characterized by a spatial correlation scale of $\sim 200 \mathrm{~m}$. It was also shown that mixing increases the width of the droplet size distribution (DSD). The characteristic time period during which an air parcel maintains its identity was found to be 15-20 min. Magaritz-Ronen et al. (2014) successfully simulated the structure of a non-drizzling stratocumulus maritime cloud observed during research flight RF01 of the Second Dynamics and Chemistry of Marine Stratocumulus field study (DYCOMS-II).

In the present paper we simulate a slightly drizzling cloud observed during research flight RF07 of the same field campaign. The study presented here addresses two questions. First, given that turbulent mixing limits the lifetime of separate cloud volumes, does the concept of "lucky" parcels as triggers of drizzle formation remain valid? Second, what is the role of mixing in this process? Especially, what is the effect of mixing of dry and warm air from the inversion on drizzle formation in the cloud? We also address the question of whether DSD broadening caused by mixing at the cloud top favors drizzle formation, or delays the process.

\section{Model description}

The model used in this study was first described in Pinsky et al. (2008) and Magaritz et al. (2009). It has been modified since the first studies were described in those papers. New processes such as surface fluxes, radiative cooling from cloud top, and most important, turbulent mixing of air parcels, have been incorporated. Some main model developments as were first presented in Magaritz-Ronen et al. (2014) are further described below.

The model contains about 2000 adjacent Lagrangian parcels with a characteristic linear size of $40 \mathrm{~m}$. The parcels cover the entire 2-D model domain of $2500 \times 1250 \mathrm{~m}^{2}$ and describe all parts of an STBL, from the ocean surface, where latent and sensible heat flux is calculated, to the top of an approximately $300 \mathrm{~m}$ deep warm and dry inversion layer. Parcels are advected throughout the domain by a turbulencelike velocity field.

The velocity field is represented as the sum of a large number of harmonics with random time-dependent amplitudes. The velocity field is assumed quasi-stationary during the entire simulation, statistically uniform in the horizontal direction, and obeys the Kolmogorov $-5 / 3$ law. Energetic and statistical properties of the velocity field are taken from observations using two measured quantities, the vertical profile of r.m.s. of velocity fluctuations, $\sigma_{w}(z)=\left\langle w^{\prime}\right\rangle^{1 / 2}$ (where $w^{\prime}$ are the fluctuations of vertical wind velocity and parentheses indicate horizontal averaging), and the lateral structure function (Pinsky et al., 2008; Magaritz et al., 2009). Microphysical processes such as diffusion growth, collisions, and sedimentation are calculated in each individual parcel. At $t=0 \mathrm{~min}$, each Lagrangian parcel contains only wetted aerosols (haze particles) and the entire boundary layer (BL) is cloud-free. Parcels are advected in the velocity field, so that some parcels may cross the lifting condensation level (LCL) and become cloudy. These parcels will contain drops as well as wetted aerosols. During the parcels' motion droplets may continue to grow or evaporate, resuming to the form of haze particles. Aerosol and drop distributions are calculated using a single 500-bin mass grid with a 0.01 to $1000 \mu \mathrm{m}$ radius range. The single bin grid allows explicit separation between haze particles in equilibrium with the environment and cloud drops with no specialized nucleation parameterization. $\mathrm{Nu}-$ cleation, diffusion growth, and partial or full evaporation are described by the full diffusion growth equation, with a small time step of $0.01 \mathrm{~s}$ to accurately describe the growth of the smallest particles (Pinsky et al., 2008; Magaritz et al., 2010). Diffusion growth of droplets is calculated on a movable mass grid, in which each bin shifts along the mass axis, according to the solution of the equation. The use of movable bins eliminates numerical spectrum broadening, while increasing the accuracy of droplet size distribution calculations.

Droplet growth by collisions is described using the stochastic equation for collisions and $1 \mu \mathrm{m}$ resolution tables for collision efficiencies presented by Pinsky et al. (2001). Collisions are performed on a regular 500-bin mass grid using the Kovetz and Olund method (1969). The great number of bins assures a high degree of accuracy in the calculation of collision growth of droplets.

One of the most prominent features of this model is that parcels are not isolated and there are two types of interaction between Lagrangian parcels: droplet sedimentation and tur- 
bulent mixing. Droplet sedimentation through parcel boundaries allows larger droplets that form in cloud parcels to act as drop collectors during their fall and reach the surface as drizzle. To calculate sedimentation the entire computational area is covered by an auxiliary regular grid with a $5 \mathrm{~m}$ resolution. Droplet flux is calculated through each of $5 \mathrm{~m}$ grid increments separating adjacent parcels.

Turbulent mixing between adjacent Lagrangian parcels is described using an expansion of $K$-theory for cases of mixing of conservative and non-conservative values (such as DSD) given on a non-regular spatial grid formed by parcel centers. The algorithm was first presented in Pinsky et al. (2010) and applied by Magaritz-Ronen (2014). The turbulent coefficient $K$ is calculated as $K(l)=C \varepsilon^{\frac{1}{3}} l^{\frac{4}{3}}$ (Richardson's law), where $l$ is the distance between parcel centers, $\varepsilon$ is the turbulent kinetic energy dissipation rate taken from observations, and $C=0.2$ (Monin and Yaglom, 1975).

To calculate mixing of DSDs, droplet flux is calculated between parcels. Because DSDs are not conservative variables, the increase or decrease in droplet size during transport from one parcel to another is taken into account according to the equation of diffusion growth. Thus, mixing at sub-grid scales is accompanied by latent heat release. This process differs from latent heat release at the resolvable scales, where supersaturation is determined by the parcel's vertical motion and droplet concentration.

Since the parcels move within an Eulerian coordinate system and droplet sedimentation is performed at the regular Eulerian finite-difference grid, the model is regarded as a Lagrangian-Eulerian Model (LEM).

Sensible and latent heat surface flux is calculated using the bulk-aerodynamic formulas, with a Dalton number of $C_{E}=0.002$ (Smith, 1988) and background wind at $10 \mathrm{~m}$ of $10 \mathrm{~m} \mathrm{~s}^{-1}$. The model's computational area is assumed perpendicular to the background wind so the wind affects only the surface flux.

Parameterization of long wave radiative cooling based on the two-stream approximation following Khvorostyanov (1995) and Khvorostyanov et al. (2003) is used in the model.

The model has periodic boundary conditions in the horizontal direction. There is no averaged air subsidence above cloud top in the model. In the STBL large-scale subsidence sharpens gradients of temperature and humidity at the upper cloud boundary and can reduce the rate of increase of cloud top height. In the model, the rate of mixing and entrainment at cloud top is determined by the slope of the $\varepsilon$ profile. With the profile used in the simulations presented here, mixing of cloud and inversion air increases cloud top height, indicating an active process of turbulence-induced entrainment.

\section{Design of simulations}

For this study the cloud observed during flight RF07 of the DYCOMS-II field campaign (Stevens et al., 2003a) was simulated in the model. The Sc measured during this night flight was $\sim 500 \mathrm{~m}$ thick and capped by a strong inversion at $825 \mathrm{~m}$. Drizzle flux at the surface in this flight was evaluated at $0.6 \mathrm{~mm} \mathrm{day}^{-1}$ (Van Zanten et al., 2005).

Measurements of the vertical profile of $\sigma_{w}(z)=\left\langle w^{\prime 2}\right\rangle^{1 / 2}$ (Stevens et al., 2005) and the lateral structure function (Lothon et al., 2005) were implemented in the model to generate the turbulence-like velocity field, with observed statistical properties. The $\sigma_{w}(z)$ maximum was equal to $0.5 \mathrm{~m} \mathrm{~s}^{-1}$ at $z=500 \mathrm{~m}$ and zero in the inversion layer, above $z=800 \mathrm{~m}$. The method for determining parameters of the turbulencelike model using these observed values is described by Pinsky et al. (2008) in detail.

The dissipation rate of turbulent kinetic energy $(\varepsilon)$ was used to calculate mixing of parcels. The dissipation rate is set to a constant value of $10 \mathrm{~cm}^{2} \mathrm{~s}^{-3}$ in the BL and decreases above cloud top. The profile and values are typical of the Sc under consideration (Lothon et al., 2005; Siebert et al., 2010; Katzwinkel et al., 2011).

Initial aerosol distribution was derived from observations (total concentration $200 \mathrm{~cm}^{-3}$, radius range $0.01-1.3 \mu \mathrm{m}$ ) and assumed to be the same for all parcels at $t=0 \mathrm{~min}$ in the boundary layer (Magaritz et al., 2009). Initial concentration of aerosols in parcels within the inversion layer was set to zero. Initial temperature and humidity profiles are assumed to be horizontally uniform at $t=0$. Initial relative humidity (RH) is set to approximately $90 \%$ below the inversion level. It decreases rapidly at heights above that level.

In this study we investigate the formation of the first largesized drops and drizzle in shallow Sc and the role of turbulent mixing in this process. To this end several simulations were performed. The control run (CON) included all processes and simulated the cloud measured during flight RF07. Supplemental simulations included a simulation with no turbulent mixing between the parcels (NoMI), a simulation with no sedimentation between the parcels (NoSd), and a simulation without mixing and sedimentation (NoMIS). Measurements from flight RF07 of the DYCOMS-II field experiment were used for validation of the model results.

\section{Results and discussion}

\subsection{Mean cloud structure}

Turbulent mixing at cloud boundaries and inside the cloud layer has a strong effect on the macroscopic properties of the cloud and drizzle formation, especially homogenization of clouds in the horizontal direction, as discussed in detail by Magaritz-Ronen et al. (2014). 

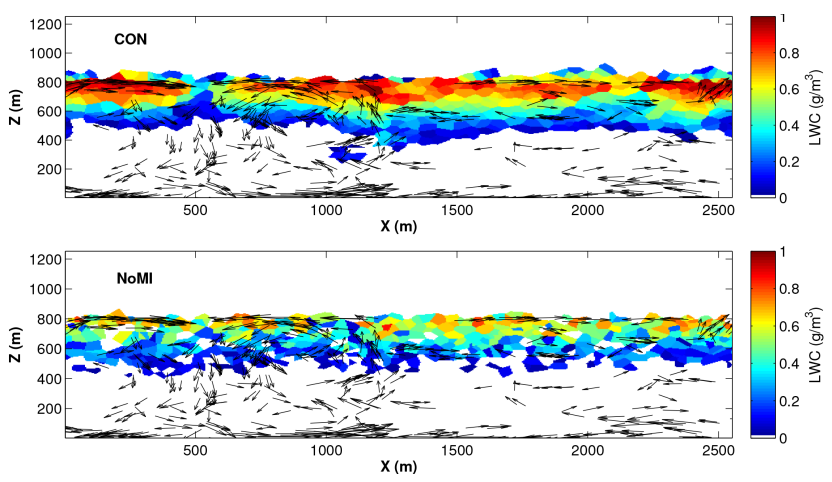

Figure 1. Fields of LWC in the CON and NoMI simulations plotted at $t=270 \mathrm{~min}$. The velocity field at the same time step is presented as well.

A snapshot of the field of LWC at $t=270 \mathrm{~min}$ in the CON and NoMI simulations is presented in Fig. 1. The time instance in the figure corresponds to the time just before drizzle formation. In the CON simulation, LWC increases with height but decreases at cloud top because of mixing with the dry and warm air above.

It is seen that in some parcels LWC exceeds $1 \mathrm{~g} \mathrm{~m}^{-3}$.The cloud is continuous in the horizontal direction, and mixing leads to a clear cloud base at $\sim 400 \mathrm{~m}$. The velocity field is also presented in Fig. 1; it can be seen that in areas of updraft cloud thickness is larger. Vertical velocity reaches $1.5 \mathrm{~m} \mathrm{~s}^{-1}$ in updraft areas $(x=1100 \mathrm{~m})$ and $-1.5 \mathrm{~m} \mathrm{~s}^{-1}$ in downdraft areas $(x=500 \mathrm{~m})$. In the study by Magaritz-Ronen et al. (2014) the spatial correlation length for several microphysical properties was calculated and found to be of the order of a few hundred meters. This value agrees with the correlation length calculated from observations for the same case.

In the NoMI case, the LWC field is highly inhomogeneous throughout the cloud, indicating a smaller radius of correlation of the order of the linear size of one parcel. Substantial inhomogeneity is also seen near cloud base, indicating a high variability in the LCL of separate parcels. One can see that in CON cloud is thicker than in NoMI, with higher cloud top and lower cloud base. This difference is the result of turbulent mixing between parcels.

Figure 2 compares the profiles of LWC, concentration, temperature, and total humidity $\left(q_{t}\right)$ in the model and observations. On average the profiles are in close agreement with observations. The inversion is well preserved for single time step and cloud and BL properties are simulated correctly. Total humidity $\left(q_{t}\right)$ and temperature increase in the model in a layer that is thicker than seen in observations between cloud top and the inversion. As mentioned, changes in the cloud top gradient are caused by turbulence-induced mixing. Supplemental simulations indicate that minor underestimation of temperature and humidity gradient above the cloud layer does not change the description of the physical mechanism of drizzle formation. Sharper temperature and $q_{t}$ gradients can be achieved in the model by using a sharper gradient of dissipation rate just above cloud top. Our choice of linear profile is based on the formation of a realistic mixing (Paluch) diagram. Note that smoother transition between cloud layer and inversion is often observed in Sc, including during the DYCOMS-II field experiment (for instance, RF03).

\subsection{Initiation of drizzle - lucky parcels}

Figure 3 shows the evolution of the median profile of the effective radius $\left(r_{\mathrm{e}}\right)$ in two simulations, $\mathrm{CON}$ (top) and NoMI (bottom). Only parcels with $\mathrm{LWC}>0.01 \mathrm{~g} \mathrm{~m}^{3}$ were used for the calculation of the median. In CON, large values of $r_{\mathrm{e}}$ are first seen near cloud top at $\sim 120 \mathrm{~min}$. The median of the effective radius increases in the lower levels of the cloud in the following time steps. The development of the median $r_{\mathrm{e}}$ is seen throughout the cloud as large drops first form near cloud top and then initiate the formation of larger droplets in the rest of the cloud. After $300 \mathrm{~min}$, large values of $r_{\mathrm{e}}$ below cloud base indicate the presence of drizzle in the BL. Drizzle formation begins when $r_{\mathrm{e}}$ at cloud top reaches $\sim 11-12 \mu \mathrm{m}$. This value corresponds with measurements (Van Zanten et al., 2005).

Examination of profiles of the median $r_{\mathrm{e}}$ at individual time steps in the CON case reveals another effect of turbulent mixing. The effective radius does not increase monotonically in the cloud and larger values of $r_{\mathrm{e}}$ can be seen close to cloud base (for example $t=100-130 \mathrm{~min}$ ). These larger values are not evident in the NoMI case and are a result of turbulent mixing. One of the mechanisms able to lead to larger $r_{\mathrm{e}}$ near cloud base is lateral mixing between descending volumes containing droplets of larger sizes with ascending volumes containing smaller droplets (Korolev et al., 2013; Pinsky et al., 2013). Effects of turbulent mixing inside the cloud on drizzle formation are further described in Sect. 4.5 and in the discussion, below.

The evolution of the $r_{\mathrm{e}}$ median profile in the NoMI case is presented in Fig. 3 (bottom panel). In the NoMI case the change in the $r_{\mathrm{e}}$ profile throughout the simulation is quite different. Parcels in this simulation are almost adiabatic; they do not mix with each other and are affected only by sedimentation of the largest droplets. Microphysical properties of each parcel in this case are determined by its initial conditions and trajectory in the BL. Using the LWC as a limit for the calculation of the median, dry parcels penetrated from the inversion layer (Fig. 1) are excluded from consideration. The profile from NoMI resembles the profile expected from an ascending adiabatic parcel where the effective radius is determined primarily by the distance above the LCL. In the NoMI case, cloud base is on average higher than in $\mathrm{CON}$, and maximum values of $r_{\mathrm{e}}$ in NoMI do not exceed $10 \mu$, indicating that large drops and drizzle do not form in this case.

Larger values of $r_{\mathrm{e}}$ in the CON case are also a result of increasing cloud depth in the simulation. During the simu- 

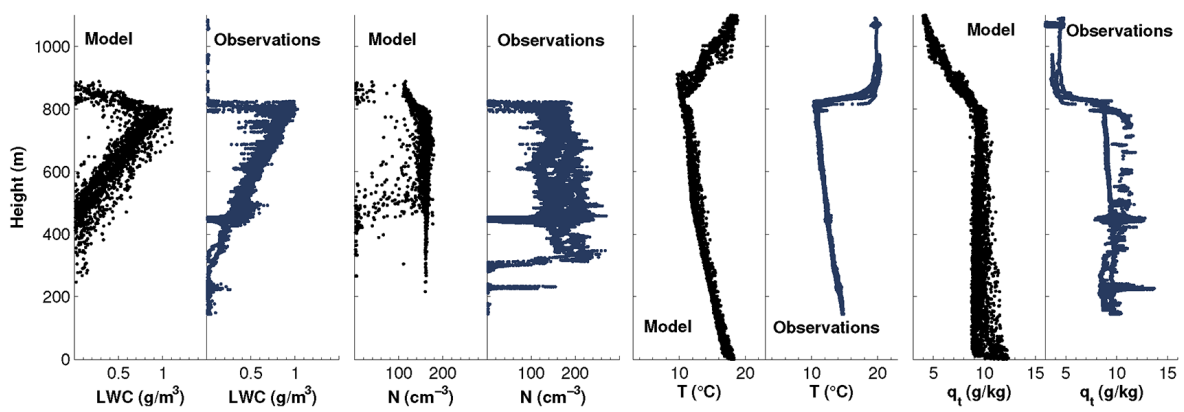

Figure 2. Profiles of LWC, droplet concentration $(N)$, Temperature $(T)$ and total water mixing ratio $\left(q_{t}\right)$ from the model simulation and observations. From the model all parcels from three time steps between 270-280 min are presented. All observations between 08:45-11:35 UTC are presented.
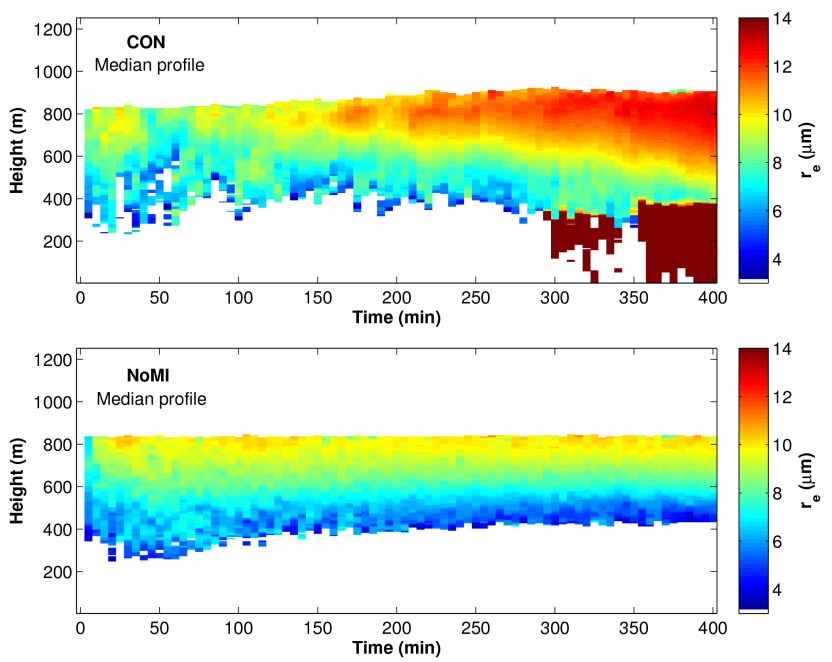

Figure 3. Changes in the effective radius median profile in the $\mathrm{CON}$ (top) and NoMI (bottom) simulations.

lation, surface fluxes lead to an increase in humidity in the subcloud layer and a lower cloud base height. In addition, cloud top height increases during the CON simulation. This is a classic manifestation of the entrainment process (Garratt, 1992). These two processes increase cloud depth and result in larger $r_{\mathrm{e}}$ near cloud top. We refer to parcels in which large droplets first form as "lucky" parcels and seek to formulate the conditions leading to their formation.

Several studies have shown that for the formation of large droplets in the DSD, efficient collisions are crucial (Pinsky and Khain, 2002; Khain et al., 2013). The rate of collisions can be characterized by the product of the square of droplet concentration and collision kernel. This product represents the gain integral in the stochastic equation of collisions (Pruppacher and Klett, 1997). Evaluations of the collision kernel conducted by Freud and Rosenfeld (2012) found that the kernel is proportional to $r_{\mathrm{e}}^{5}$. Accordingly, for a given DSD the collision rate can be characterized by a collision parameter in the form of $N^{2} r_{\mathrm{e}}^{5}$. Figure 4 describes the depen-

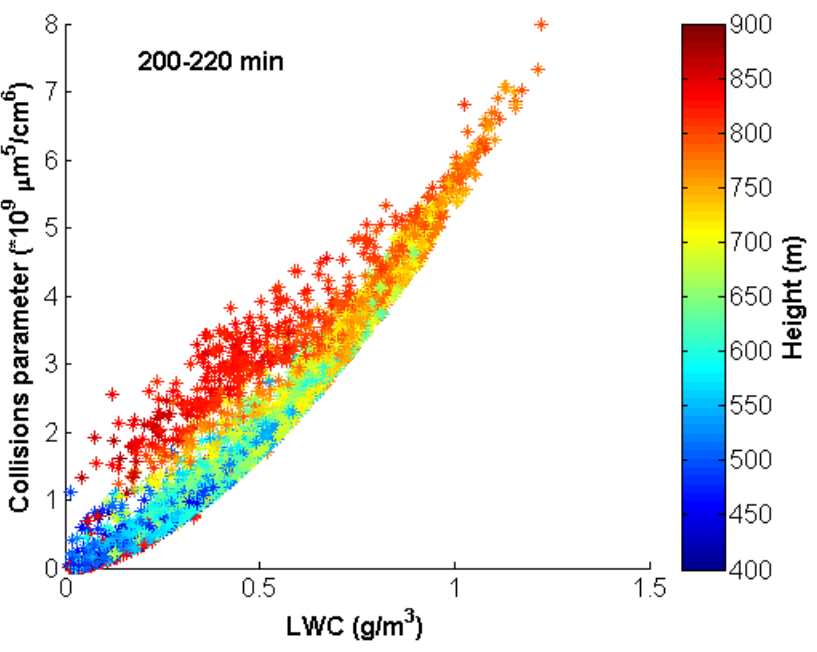

Figure 4. LWC vs. collision parameter scatter plot for all cloud parcels at 200-220 min of simulation in the CON case. Color denotes the height of the parcel.

dence of the collision parameter on LWC. There is clear dependence between the two parameters and as LWC increases so do the collisions in the parcel. An increase is also seen as the height of the parcel in the cloud increases. This is expected, given the strong LWC-height correlation. According to results presented in Fig. 4, as LWC increases the probability of the formation of large drops increases. The importance of maximum LWC values in the formation of drizzle was also stressed by Khairoutdinov and Kogan (2000) and Magaritz et al. (2009) and is the first characteristic of a "lucky" parcel.

Figure 5 illustrates the mechanism of formation of parcels with maximum values of LWC. This figure shows the field of humidity at $t=150 \mathrm{~min}$ (top panel). The dry inversion and the well-mixed BL are clearly seen. Moisture flux from the ocean surface lead to an increase in humidity in parcels located at the lower levels of the domain. These high-humidity areas expand upwards towards the cloud in updrafts related to large eddies (convective cells, rolls). Large eddies are a typi- 

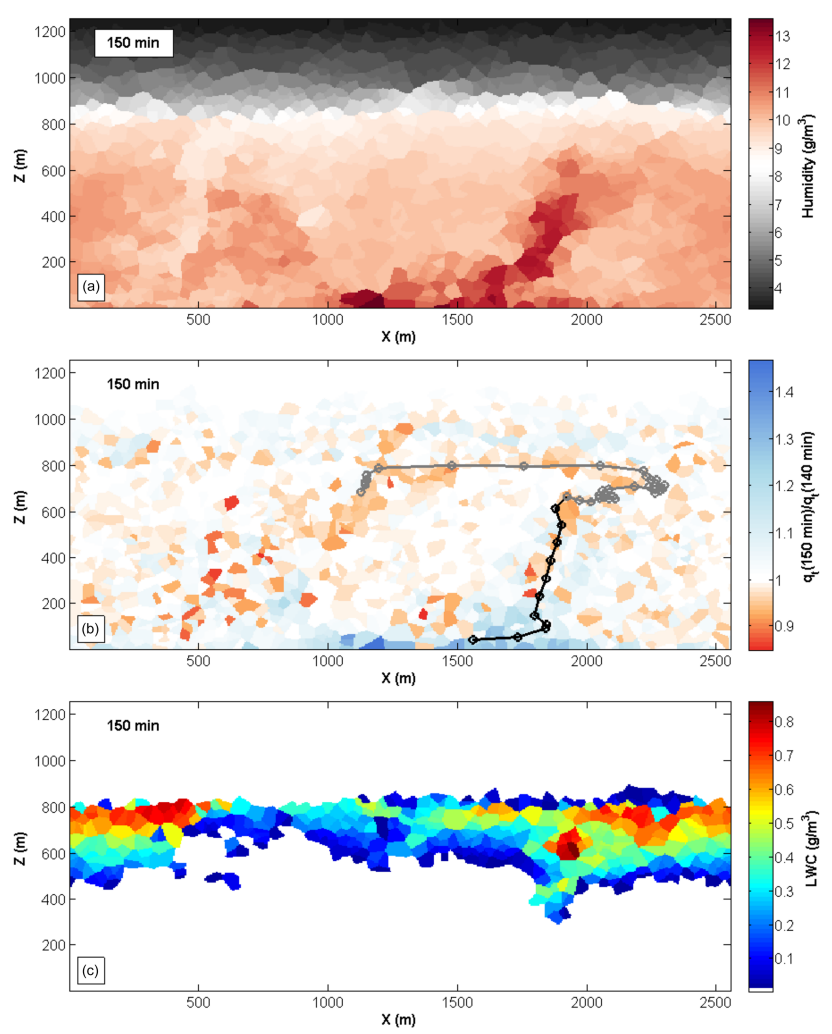

Figure 5. Fields of different parameters plotted at $t=150 \mathrm{~min}$. (a) Humidity; (b) total water mixing ratio: $q_{t}(150 \mathrm{~min}) / q_{t}(140 \mathrm{~min})$; (c) LWC.

cal feature of marine boundary layers (Stevens et al., 2003b, 2005; Ginis et al., 2004) and are reflected in the velocity field of the model. The updraft velocities in such cells can exceed $2 \mathrm{~m} \mathrm{~s}^{-1}$ and the width of the updraft can be as large as a few hundred meters.

A previous study (Magaritz-Ronen et al., 2014) found that with turbulent mixing the lifetime of a single $40 \mathrm{~m}$ parcel is of the order of $\sim 15-20 \mathrm{~min}$. The lifetime of a parcel is defined here as the time it takes for a parcel to mix with its environment and conservative properties of the parcel become similar to those in its surrounding. During this time period the parcel can be distinguished from surrounding parcels, and can be tracked and analyzed. But gradual changes occur during its lifetime. Examination of a conservative value such as total water content $\left(q_{t}\right)$ enables us to evaluate the extent to which an air volume mixes with its neighboring parcels. The middle panel in Fig. 5 presents the ratio between $q_{t}(150 \mathrm{~min})$ to $q_{t}(140 \mathrm{~min})$ for all parcels in the model. Parcel locations in the figure are according to their location at $t=150 \mathrm{~min}$. Parcels mix with their environment at different rates, as a function of the gradient between the parcel and its immediate environment. For some of the parcels near the surface $q_{t}$ increases during this period. The ascending branch of humidity, as identified in the top panel, is wider than a single parcel, allowing the parcels in the center of the branch to lose less $q_{t}$ than adjacent parcels. During their ascent (here of $10 \mathrm{~min}$ ), parcels may lose up to $10 \%$ of $q_{t}$. These ascending parcels also have a lower lifting condensation level (LCL) (bottom panel). Parcels with high $q_{t}$ will later have a high LWC in the cloud. The trajectory of a single parcel between 140-150 min is marked in black in the middle panel. The trajectory of the same parcel between 150-160 min is marked in gray. After a rapid ascent, the selected parcel moves along the cloud top. As emphasized in the following sections, this is the preferred trajectory for a "lucky" parcel forming the first large drops in the cloud.

The process of lucky parcel formation is further illustrated in Fig. 6a. All parcels located at the bottom of the domain, near sea surface at $t=145 \mathrm{~min}$, were selected. These parcels have varying humidity values, depending on flux from the ocean surface and the history of the parcel. This is the $x$ axis of the plot. The $y$ axis is the LWC marked at 5-min increments. The colors denote the height of the parcel. After 5 min, small values of LWC are seen in some parcels. The LCL of these parcels is about $\sim 300 \mathrm{~m}$, although the cloud base has an average height of $\sim 400 \mathrm{~m}$. These parcels have maximum values of humidity. Parcels of this type are similar to the one marked in Fig. 5. After another 5 min, more parcels ascend and the ones reaching $600 \mathrm{~m}$ have largest LWC. Parcels with the highest initial humidity will have the highest LWC as well. This trend also continues for a further $5 \mathrm{~min}$. As expected, a strong dependence on the height of the parcel is evident in the scatter. In the last panel, after 20 min of simulation, the clear slope disappears and the LWC is determined mostly by the height of the parcel in the boundary layer. Only parcels with maximum values of LWC are shown in panel b. In the figure it is shown that even with the strong dependence on the height of the parcel, parcels with maximum LWC at cloud top have maximal initial humidity values. The mechanism described can be summarized as follows. In adiabatic (or close to adiabatic) parcels LWC increases inside the cloud as adiabatic LWC. For maximum LWC values at cloud top, the LCL should be minimal for such a parcel. The low LCL is determined by high RH in the parcel. Such high RH can be obtained from the ocean surface.

Figure 7 presents the evolution of microphysical parameters of a single parcel. This parcel, which is marked in Fig. 6a by black circles in all panels, ascends from cloud base to $800 \mathrm{~m}$ in $13 \mathrm{~min}$ (panel b). The effective radius in the parcel increases to $12 \mu \mathrm{m}$ during this time. The formation of drizzlesized drops (droplets with radius exceeding 25-30 $\mu \mathrm{m}$ ) substantially accelerates at $t=160 \mathrm{~min}$, when $r_{\mathrm{e}}=11 \mu \mathrm{m}$ and LWC reaches $1 \mathrm{~g} \mathrm{~m}^{-3}$. In the DSD (panel b) an elongated tail of largest droplets is formed. Towards $t=166 \mathrm{~min}$, the parcel contains drizzle droplets with radii as large as $40 \mu \mathrm{m}$ (Fig. 7b). A tail of large drops was also reported in observations (Van Zanten et al., 2005). The concentration of these drops remains small and does not increase $r_{\mathrm{e}}$ significantly. 


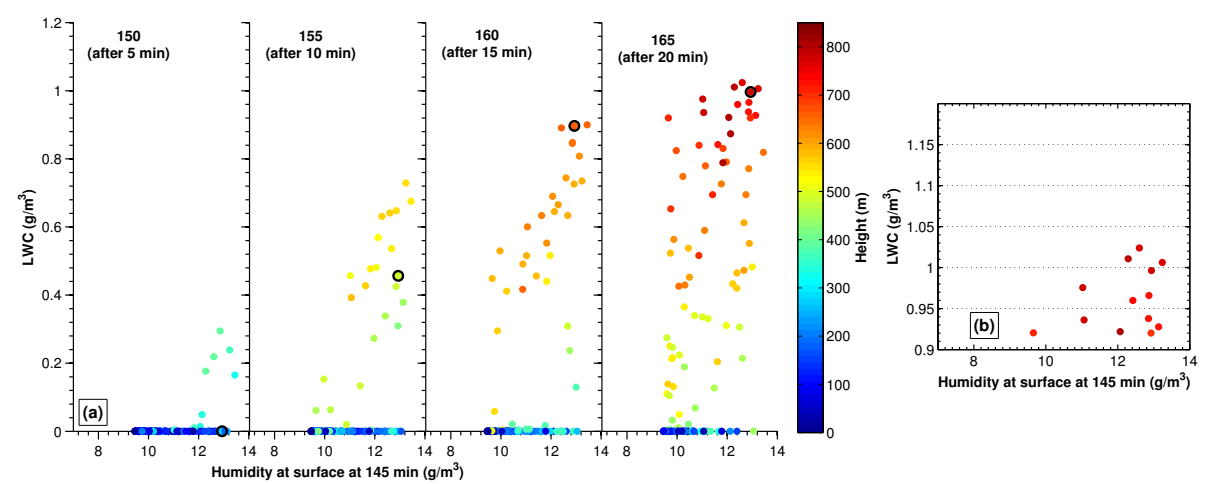

Figure 6. (a) LWC as a function of humidity at the surface at 5 min intervals, starting at 145 min of simulation in the CON case. A single selected parcel used in Fig. 8 is marked in black in all panels. (b) Magnification of the top part of the last panel in (a).
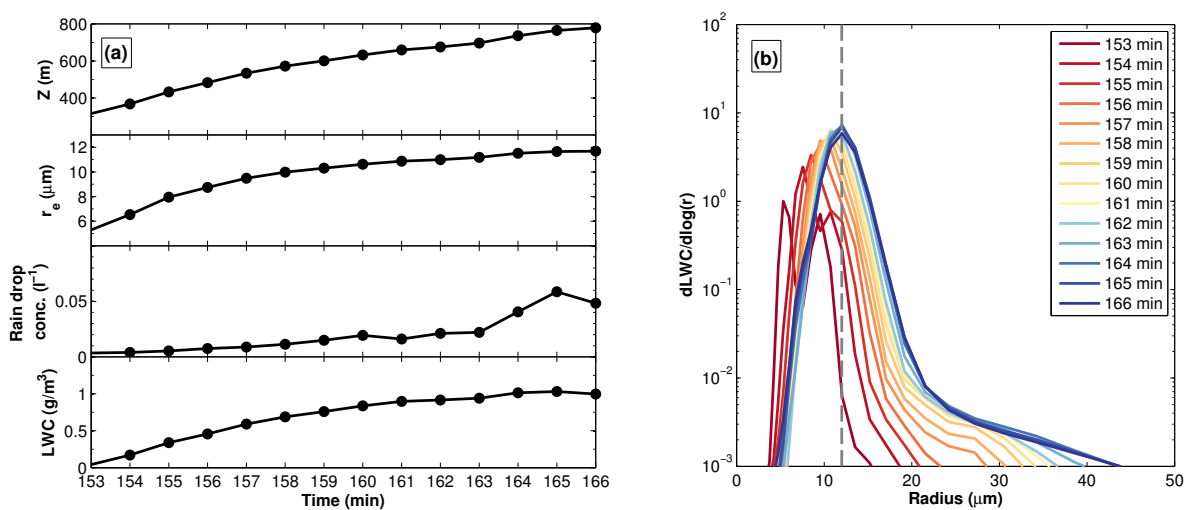

Figure 7. History of a single parcel marked in Fig. 6. (a) Change in the height, effective radius, rain drop concentration, and LWC of the parcel. (b) Changes in the mass distribution of the parcel.

The peak of the DSD appears at $r \approx 11-12 \mu \mathrm{m}$. After the time steps shown in the figure, large droplets are lost from the DSD by sedimentation.

In Fig. 8 we examine only those parcels that reach a value of LWC greater than $0.8 \mathrm{~g} \mathrm{~m}^{3}$. Along the $x$ axis, the time each parcel retained the high LWC value is plotted. The maximum collision parameter value during this period is shown along the $y$ axis in the diagram. The color denotes the maximum value of LWC during the same time period. As the length of time the parcel has high LWC increases, the collision rate in the parcel increases as well. However, after the parcel has a residence time of more than 10-12 min with high LWC, the collision parameter no longer increases. Sedimentation of the larger drops forming in the parcel reduces the LWC and collision parameter. Not all parcels can retain the high LWC and intense collisions for the duration presented in Fig. 8. For this to occur a parcel needs to first be located near cloud top, where LWC is maximal, but not too close to the inversion layer, where mixing with dry air may lead to loss of LWC.

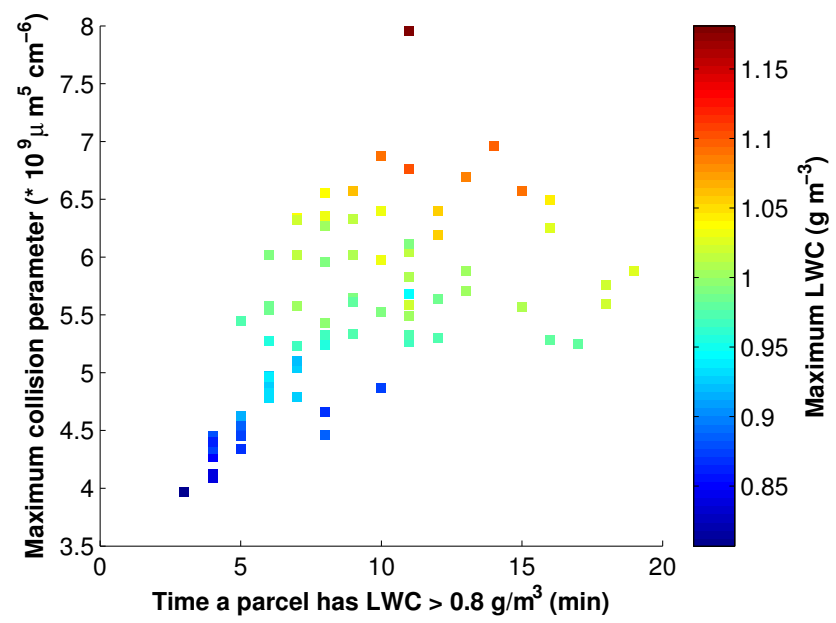

Figure 8. Maximum collision parameter as a function of the accumulated time a parcel has $\mathrm{LWC}>0.8 \mathrm{~g} \mathrm{~m}^{-3}$. Colors denote the maximum value of LWC during the same time period. 


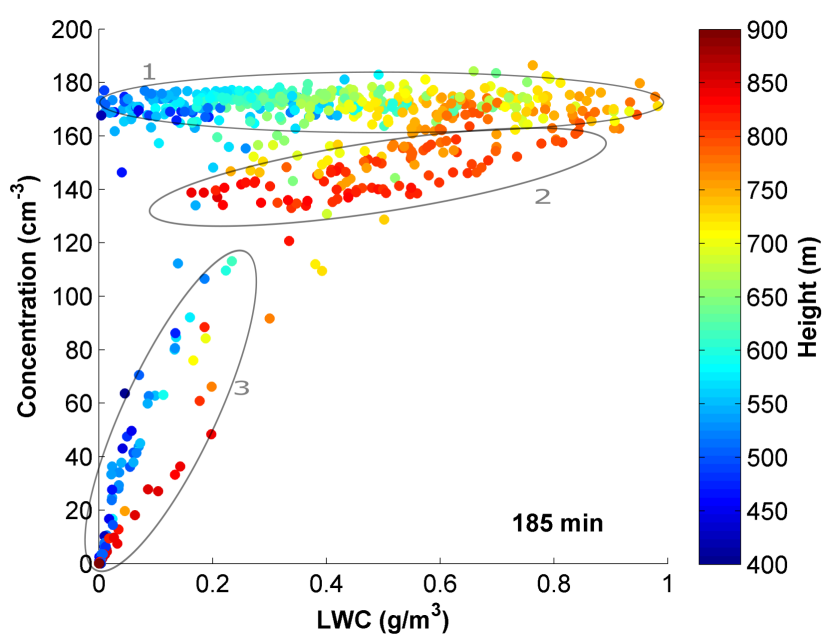

Figure 9. LWC vs. $N$ scatter plot at $t=185 \mathrm{~min}$. Colors denote the height of the parcel.

\subsection{Interaction between cloud top and inversion}

The first large droplets form near cloud top, where mixing with dry environment is most pronounced. Inhomogeneous mixing is often suggested as a mechanism leading to increase in the maximum drop size in ascending cloud volumes mixing with the environmental in cumulus clouds (Baker et al., 1980; Baker and Latham, 1982; Lasher-Trapp et al., 2005; Cooper et al., 2013), it is therefore of interest to investigate the possibility that turbulent mixing at cloud top of Sc may accelerate the formation of these droplets.

Figure 9 shows a scatter diagram of droplet concentration and $\mathrm{LWC}(\mathrm{LWC}-N)$. Each point in the diagram marks a single parcel at $t=185 \mathrm{~min}$. Colors denote the height of the parcels. Parcels in the diagram can be separated into three zones. In zone 1 air parcels are close to adiabatic, as indicated by the high droplet concentration. Parcels in this zone are ascending in the cloud and droplets grow by diffusional growth. Droplet concentration in the parcels remains nearly the same, but LWC increases with height. In zone 2 cloud parcels are located near cloud top for longer periods of time. Turbulent mixing of these parcels with parcels from the inversion layer leads to a decrease in droplet concentration and LWC. However, LWC decreases more substantially than concentration, indicating partial evaporation of droplets in the DSD and penetration of small droplets from neighboring initially dry parcels. The decrease in droplet concentration is only of the order of $10 \%$. In zone 3 the slope of the relationship changes. In this zone parcels initially from the inversion layer become cloud parcels, due to mixing with adjacent cloud parcels. Both droplet concentration and LWC in these parcels are smaller than in the initially adiabatic cloud parcels. Since LWC and concentration are initially zero in these parcels, every droplet that enters the parcel and does not evaporate completely increases these values substantially, leading to the
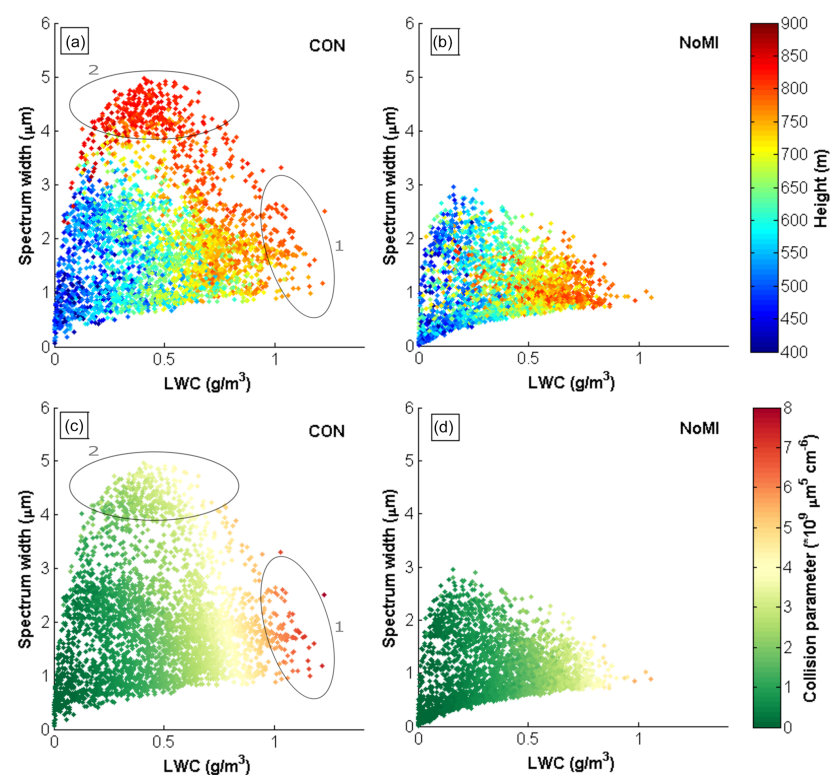

Figure 10. LWC vs. spectrum width scatter diagrams for the CON (left) and NoMI (right) cases. Each dot represents a parcel during 195-220 min of simulation. In the top row $(\mathbf{a}, \mathbf{b})$ colors denote the height of the parcel. In the bottom row $(\mathbf{c}, \mathbf{d})$ colors denote the collision parameter.

larger slope of data points in zone 3. Changes in droplet concentration also lead to changes in the DSD spectrum width, which is demonstrated in Fig. 10.

Figure 10 compares DSD widths (standard deviation of the distribution) as a function of LWC in simulations with (CON, panels a, c) and without mixing (NoMI, panels b, d). In the CON case the spectrum width values are higher than in the NoMI case. In CON, DSD width is maximal in zone 2, where mixing leads to the formation of small droplets and broadening of DSD. These parcels correspond to the parcels in zone 2 in Fig. 9, where the decrease in LWC is seen to be greater than the concentration. As mentioned above, partial evaporation of droplets in these parcels is the principal process leading to broadening of DSD toward smaller drops and increasing spectrum width. While spectrum width is greatest in parcels at cloud top, the strongest collisions are in the most adiabatic parcels with the largest LWC (zone 1). These parcels may have lower DSD width, because they contain fewer small droplets. In parcels that interact with the inversion air, mixing with dry environmental air increases spectrum width towards smaller drops and decreases the rate of collisions. If sufficiently large drops formed in the parcel before it mixed with the dry inversion air, collisions can still be efficient and drizzle-size drops may form.

In adiabatic parcels, the spectrum width is determined by a combination of the initial spectrum at cloud base and the path of the parcel in the cloud. The initial DSD is a function of the supersaturation at the LCL and the aerosol distribution. Further ascent of the parcel is accompanied by diffusion 
growth and, if conditions permit, the beginning of collisions and widening of the DSD towards large drops. Variability of spectrum width values increases when the parcels are not adiabatic (Fig. 10). In the case of turbulent mixing, the width of an individual spectrum is not a direct result of the parcel's history but also of the history of adjacent parcels. These wider DSD may expedite drizzle formation in the cloud. But in general, we see that the DSD width is not the main factor that fosters intense collisions and in our case first drizzle drops. Diffusion growth leads to DSD narrowing in the space of drop radius; in the space of $r^{2}$ DSDs are shifted to large sizes without change in the shape of the distribution. Since relative velocities between droplets are proportional to $r^{2}$, diffusion growth leads to increase in the collision kernel and collision rate despite DSD narrowing in the radii space. The main conclusion from this analysis is that maximum drop size is reached in parcels close to adiabatic, but not in parcels with wide DSD formed under effects of mixing.

It is interesting to note that in addition to a higher collision parameter, LWC maximum values are greater in the CON case than in the NoMI case as well. These higher LWC values indicate a deeper cloud. During the simulation, sensible and latent heat fluxes from the surface increase the humidity in the boundary layer and lead to a decrease in cloud base height as was mentioned above. These changes result in an increase of the LWC max near cloud top.

Conclusions inferred from the previous figures regarding the shape of the DSD are supported by Fig. 11, where DSDs at $100 \mathrm{~m}$ layers near cloud top are presented. The DSDs are separated by LWC value and averaged in the horizontal direction. For all presented DSDs the distribution peak is located at similar radii. The concentration of drops around $10 \mu \mathrm{m}$ increases with the increase in the LWC at each height. In addition, DSDs with lower LWC have a higher concentration of small droplets. DSDs in this figure all come from near cloud top and the decrease in LWC, decrease in the larger drop concentration, and formation of smaller droplets result from turbulent mixing with the dry inversion air. These DSDs correspond to the parcels in zone 2, in Figs. 9 and 10. So, according to our results, mixing does not lead to the formation of superadiabatic droplets that trigger collisions. On the contrary, droplets of maximum size arise in parcels close to adiabatic (undiluted).

Note that mixing between parcels in the model is inhomogeneous, because it takes significant time $(15-20 \mathrm{~min})$ for homogenization (according to homogeneous mixing homogenization is instantaneous). At the same time mixing leads to DSD broadening. This contrasts with the classical theory that assumes the shape of DSD to be unchangeable in the case of extreme inhomogeneous mixing. We attribute this difference to the simplifying assumption of monodisperse DSD in the classical mixing concepts.

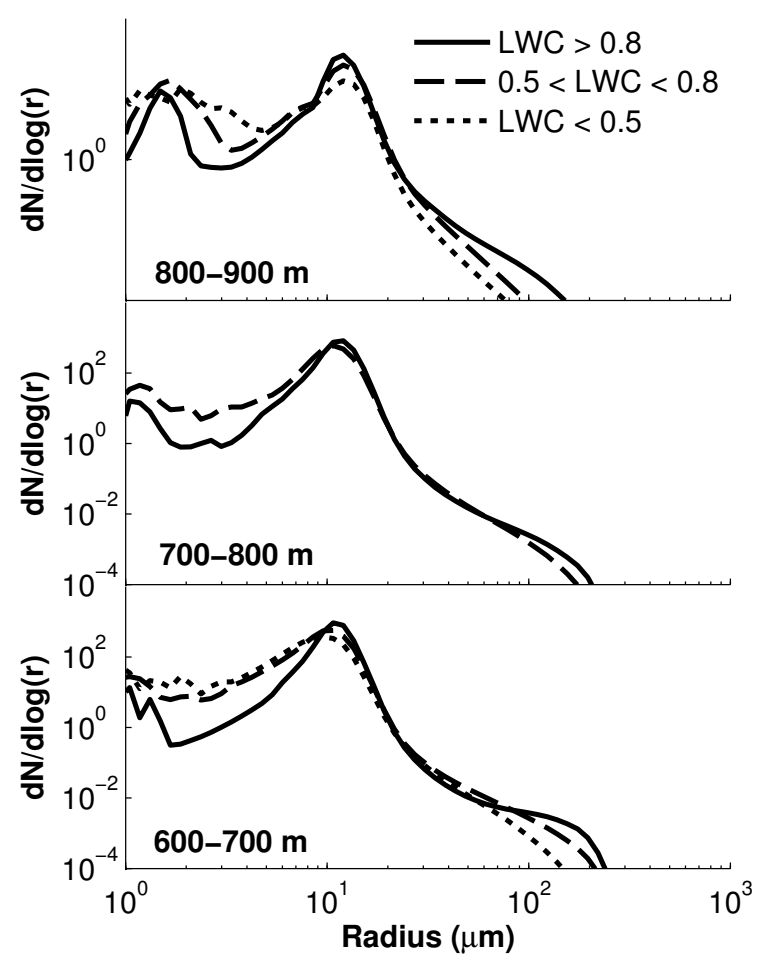

Figure 11. Averaged DSD at three layers near cloud top. At each level DSD is averaged according to LWC value.

\subsection{The dual role of turbulent mixing in formation of drizzle}

In previous sections we discussed the properties of "lucky" parcels where first drizzle is formed. "Lucky" parcels have high absolute humidity. They originate from near the surface and reach the upper levels of the cloud quickly, not allowing sufficient time for mixing with the surrounding air. In these parcels collisions lead to the formation of drizzle followed by sedimentation of the largest drops.

In this section we wish to observe the effects of turbulent mixing on the formation of "lucky" parcels as well as on the further development of drizzle in the cloud. Figure 12 compares the accumulated mass and accumulated number of drops larger than $20 \mu \mathrm{m}$ in all parcels in the domain for different simulations.

Large droplets first form in cases where drop sedimentation is removed. In these simulations drops become very large and grow by collisions to unrealistically large sizes, and yet they provide insight into the process of first drizzle drop formation.

In the NoMISD case the mass increases faster and earlier in the simulation than in the NoSD case. When the parcels are adiabatic, parcels initially located near the surface where humidity is maximal will have the lowest LCL and maximum LWC. In the NoMISD these parcels retain their extreme values of humidity and large drops form earlier. Inclusion of 

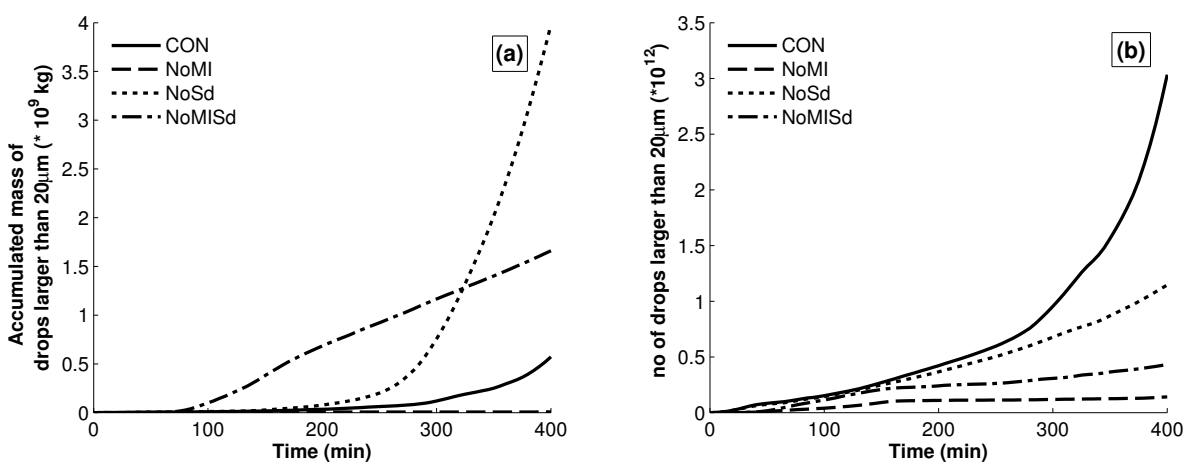

Figure 12. Accumulated mass (a) and concentration (b) of drops larger than $20 \mu \mathrm{m}$. Four simulations are presented: control (CON), nomixing (NoMI), control and no sedimentation (NoSd), and no-mixing and no sedimentation (NoMISd).

mixing between the parcels leads to a reduction of maximum values, homogenization of the BL, and a subsequent delay in the formation of large droplets (NoSd, left panel). From these results it can be seen that the first large droplets will form in adiabatic parcels with initially high humidity. The accumulated number of large drops (right) further supports this conclusion. In NoMISD the number of large drops increases until $\sim 150 \mathrm{~min}$ and then remains almost constant. Following the formation of large droplets in parcels with appropriate conditions no more parcels are able to reach these conditions. In contrast, the number of large drops in the NoSD run continues to increase after $150 \mathrm{~min}$ of simulation. The absence of turbulent mixing is the only difference between the two simulations and yet the changes in the mass and number of larger drops are significant. Results indicate that the direct effect of mixing on parcels with initially high humidity and low LCL is to retard the formation of large droplets.

When sedimentation is included in the simulations, after some drops become large enough they may fall through the cloud. In the NoMI case large drops forming in a small number of parcels sediment through the cloud and evaporate in other parcels, especially in dry and warm parcels penetrated from the inversion (Fig. 1). As a result, the amount of large droplets that form in the cloud remains very low and the mass of these large drops is negligible. This evaporation process prevents the formation of drizzle at the surface in the NoMI case. In CON simulation, when mixing is included, the cloud structure changes dramatically. As a result, droplets falling from parcels close to adiabatic do not evaporate but grow by collisions within the cloud. In this simulation drizzle develops and reaches the surface. After the initial formation of large drops in the most humid parcels in the cloud, the number of large drops in the CON case continues to increase, indicating that turbulent mixing facilitates the formation of drizzle in the cloud.

In general, Fig. 12 shows the two main phases of drizzle formation in Sc. First, larger droplets form in the most adiabatic parcels in the cloud layer. Second, turbulent mixing leads to further formation of more large droplets and drizzle-

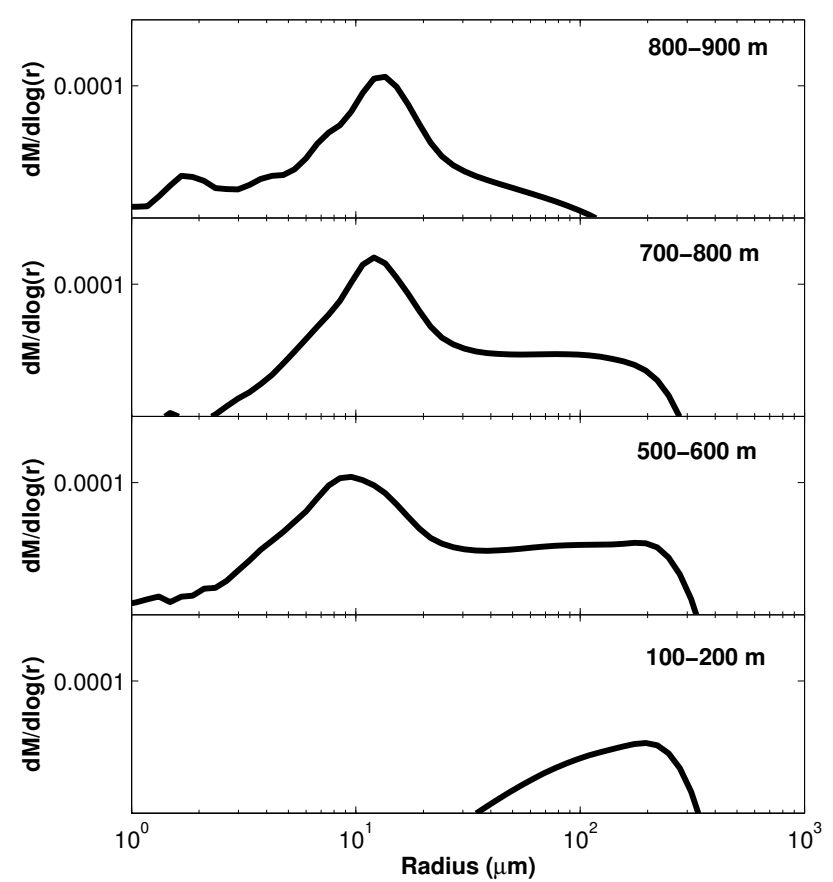

Figure 13. Averaged mass distribution for $100 \mathrm{~m}$ layers, plotted at $t=360 \mathrm{~min}$ in the CON simulation.

sized drops. In these two phases turbulent mixing plays a contradictory role, delaying the first while enhancing the second (see further detail in the discussion).

\subsection{Further drizzle development in the cloud}

In the cloud's latter stages of drizzle development, large drops forming in "lucky" parcels sediment through the cloud, leading to further development of drizzle. In Fig. 3 this process is first seen as an increase of $r_{\mathrm{e}}$ throughout the cloud layer. The horizontally averaged mass distribution in the simulated cloud at the drizzle stage $(t=360 \mathrm{~min})$ is shown in Fig. 13. At this time drizzle drops reach the surface. Figure 13 shows that large drops form first at the top (700- 


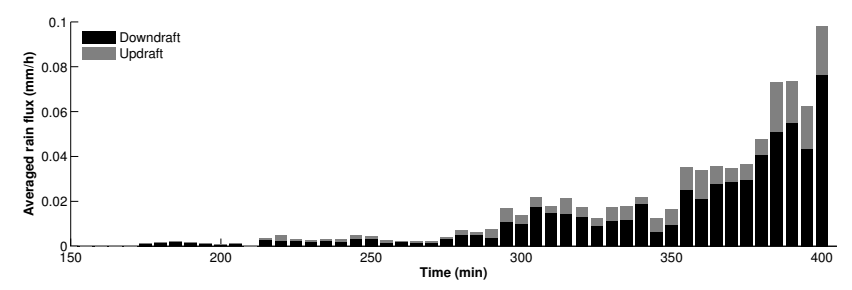

Figure 14. Averaged rain flux at $450 \mathrm{~m}$ near cloud base, separated into downdraft (black) and updraft (gray) areas.

$800 \mathrm{~m}$ ) and then sediment through the cloud. During their descent the drops grow and their relative proportion in the mass distribution increases. As the droplets from cloud top sediment through the cloud they act as drop collectors, growing in size through collisions and coalescence. Near the surface $(100-200 \mathrm{~m})$ there are only large drops in the distribution which were large enough to reach these levels and not evaporate in the sub-cloud layer. The radius of drizzle drops ranges from 40 to $350 \mu \mathrm{m}$, with a peak at $200 \mu \mathrm{m}$. These radii agree with observations (Pinsky et al., 2008).

The dynamic structure of the BL and the presence of large eddies affect the continuation of drizzle development in Sc clouds as well. They determine areas of updraft and downdraft and are the controlling factor in the preferable trajectory of "lucky" parcels. As larger drops form along cloud top, droplets in parcels reaching areas of downdraft are more prone to sedimentation. Drizzle does not develop in the entire cloud simultaneously so that areas of more intense drizzle flux form. These areas coincide with downdraft areas in the cloud. Figure 14 presents the averaged rain flux near cloud base $(450 \mathrm{~m})$ throughout the simulation. Each bar shows the drizzle flux separated into downdraft and updraft areas. It can be seen that most of drizzle falls in these areas. Areas of enhanced drizzle were seen in observations of RF07 as well (Van Zanten et al., 2005).

In Fig. 14 it was shown that the mass and number concentration of larger drops increase when turbulent mixing is taken into account - far beyond those seen with no mixing. In addition to the inhibiting effect mixing has on the initiation of drizzle, turbulent mixing is needed for continued drizzle development in the cloud.

Among possible mechanisms able to lead to this effect we first consider changes to the aerosol size distribution. One of the specific features of the model used in this study is accounting for the aerosol distribution in each parcel. In addition to accounting for aerosols when the parcel is subsaturated and all aerosols are in equilibrium with the environment, the model tracks aerosols in the drops themselves. Aerosol size does not change during processes of diffusion growth or evaporation, but in cases of collisions aerosol size grows and may reach larger sizes than initially found in the BL. Figure 15 presents the development through time of the maximum aerosol size in cloud parcels. The median profile
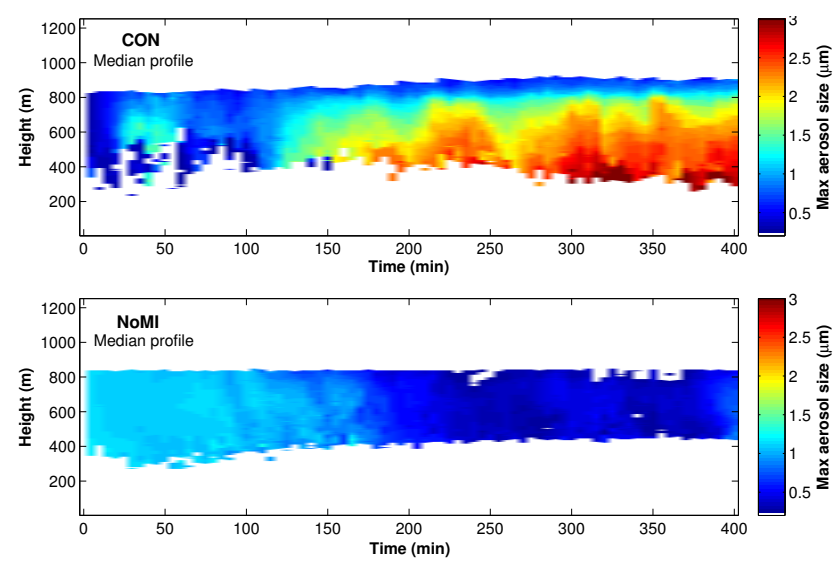

Figure 15. Change in the median profile of the maximum aerosol size in cloud parcels in the CON (top) and NoMI (bottom) case.

of the maximum aerosol size in each parcel for the CON (top) and NoMI (bottom) cases is presented.

First, it is clear that the changes in the maximum aerosol size are very different in the two cases. In the NoMI case, largest aerosols are present at the beginning of the simulation. These aerosols have an average size of $1.3 \mu \mathrm{m}$, corresponding to the largest aerosol in the input spectrum. As the largest aerosols in the spectrum they will be in the largest drops in the DSD. After about $150 \mathrm{~min}$, aerosol size diminishes. In NoMI, sedimentation of the largest droplets from parcels with the lowest LCL results in the largest aerosols in drier and warmer parcels. These parcels do not have the conditions required for larger drop formation in the following time steps. Because of the comparatively small number of parcels with appropriate initial conditions, sedimentation of the largest drops renders the largest aerosols unavailable for further collisions.

As seen in the previous section, initial conditions are a governing factor in the formation of large drops when the parcels are adiabatic, and drop formation will be much more rapid without mixing than in the case of mixing.

As the development of the cloud progresses in the CON case the maximum aerosol size increases and reaches an average of more than $3 \mu \mathrm{m}$. When turbulent mixing is included maximum values of humidity and LWC are reduced and initial droplets forming in the cloud are somewhat smaller. These drops do not sediment to the surface, but evaporate in the sub-cloud layer. The aerosols can now be advected back into the cloud in ascending branches of large eddies. As aerosols recirculate in the BL, their size increases when they are inside droplets growing by collisions and coalescence. The mechanism for aerosol size increase is presented in a study by Magaritz et al. (2010) showing that the evolution of large drops in Sc leads to a corresponding increase in the aerosol size distribution as a result of collisions inside the cloud. 
Mixing between parcels gives rise to the recirculation of aerosols in the cloud. Collisions lead to the formation of increasingly large droplets and aerosols during the recirculation. As a result, the maximum size of aerosols at cloud base increases which fosters the formation of larger droplets at cloud base (large haze particles) and above in ascending parcels. We believe that the droplets formed on the largest aerosols contribute to the formation of the tail of largest droplets in lucky parcels shown in Fig. 7b. After initiation of drizzle in the cloud, enhanced collisions and formation of drizzle leads to a rapid increase in aerosol size as clearly shown in Fig. 15. Larger aerosols continue to circulate in the $\mathrm{BL}$, fostering further drizzle formation at the drizzle stage of cloud evolution.

Spectral broadening and formation of the largest droplets in Sc due to turbulent mixing during vertical recycling of cloud air is discussed in a study by Korolev et al. (2013). In that study it is suggested that mixing of the DSD of parcels ascending and descending in the cloud should lead to the presence of larger droplets in the ascending branch of the cloud near cloud base and result in more efficient collisions as the parcel ascends. The results seen in Fig. 15 can also foster formation of larger droplets in ascending parcels, during the course of diffusion growth and collisions. In combination with the increased spectral width seen in Fig. 10 and the increase in the median profile of $r_{\mathrm{e}}$ near cloud base that is shown in Fig. 3 we believe that lateral mixing near cloud base and inside the cloud layer can have a strong effect on the drizzle formation process in Sc.

\section{Conclusions}

The process of drizzle formation in Sc is investigated using LEM, with an accurate description of microphysical processes. The new version of the model includes the process of mixing between parcels and surface flux of heat and moisture. Lightly drizzling stratocumulus clouds observed during flight RF07 of the DYCOMS-II field campaign were successfully simulated.

Clouds observed in flight RF07 were simulated by an earlier version of LEM, where there was no mixing between parcels and no inversion layer above cloud top (Magaritz et al., 2009). In that study the hypothesis that first drizzle forms in a small number of air volumes near cloud top in which LWC is maximal was expressed and justified. The consideration of a more realistic geometry of the STBL with an inversion layer required the implementation of turbulent mixing between the Lagrangian parcels. The question arose, whether the hypothesis of "lucky" parcels can also be justified under conditions of mixing. Results of the present study show that the hypothesis of "lucky parcels" remains valid also when turbulent mixing is taken into account.

It was further shown that mixing creates a realistic structure of stratocumulus clouds but does not prevent the appear- ance of nearly adiabatic LWC values at cloud top. Among these air volumes in the cloud "lucky" parcels are the most humid and have the highest LWC and the most intense collisions.

It is shown that without mixing taken into account drizzle cannot form in stratocumulus clouds. Maximum LWC values are not as high and large drops can form only in a smaller portion of the parcels that reach cloud top. Effective radius in the cloud is lower and its linear profile remains nearly constant throughout the lifetime of the cloud.

In conclusion, turbulent mixing plays a dual role in the process of drizzle formation. On the one hand, the formation of the first large drops in Sc is an adiabatic process in which turbulent mixing is an inhibiting factor. It reduces maximal values of humidity and delays the formation of the first drops. On the other hand, turbulent mixing leads to the creation of generally favorable background conditions and increased aerosol size within clouds, allowing drizzle growth and development during drop sedimentation. In addition, mixing leads to an increase in the drop size (haze size) at cloud base leading to faster formation of largest drops in the ascending nearly adiabatic cloud volumes.

Acknowledgements. This research was supported by the Israel Science Foundation (grant 1393/14), the Office of Science (BER), the US Department of Energy Award DE-SC0006788, and the Binational US-Israel Science Foundation (grant 2010446). The authors express their gratitude to A. Kostinski for ideas about the existence of lucky parcels, where first drizzle forms.

Edited by: M. Petters

\section{References}

Ackerman, A. S., Van Zanten, M. C., Stevens, B., Savic-Jovcic, V., Bretherton, C. S., Chlond, A., Golaz, J.-C., Jiang, H., Khairoutdinov, M., Krueger, S. K., Lewellen, D. C., Lock, A., Moeng, C.-H., Nakamura, K., Petters, M. D., Snider, J. R., Weinbrecht, S., and Zulauf, M.: Large-Eddy Simulations of a Drizzling, Stratocumulus-Topped Marine Boundary Layer, Mon. Weather Rev., 137, 1083-1110, doi:10.1175/2008MWR2582.1, 2009.

Baker, M. B. and Latham, J.: A diffusive model of the turbulent mixing of dry and cloudy air, Q. J. R. Meteorol. Soc., 108, 871898, doi:10.1002/qj.49710845809, 1982.

Baker, M. B., Corbin, R. G., and Latham, J.: The influence of entrainment on the evolution of cloud droplet spectra: I. A model of inhomogeneous mixing, Q. J. R. Meteorol. Soc., 106, 581-598, doi:10.1002/qj.49710644914, 1980.

Brenguier, J.-L. L., Pawlowska, H., Schuller, L., Preusker, R., Fischer, J., Fouquart, Y., and Schüller, L.: Radiative Properties of Boundary Layer Clouds: Droplet Effective Radius versus Number Concentration, J. Atmos. Sci., 57, 803-821, doi:10.1175/1520-0469(2000)057<0803:RPOBLC>2.0.CO;2, 2000.

Cooper, W. A., Lasher-Trapp, S. G., and Blyth, A. M.: The Influence of Entrainment and Mixing on the Initial Formation of 
Rain in a Warm Cumulus Cloud, J. Atmos. Sci., 70, 1727-1743, doi:10.1175/JAS-D-12-0128.1, 2013.

Feingold, G., Kreidenweis, S. M., Stevens, B., and Cotton, W. R.: Numerical simulations of stratocumulus processing of cloud condensation nuclei through collision-coalescence, J. Geophys. Res., 101, 21391-21402, 1996.

Feingold, G., Cotton, W. R., Kreidenweis, S. M., Davis, J. T., and Avis, J. A. T. D.: The Impact of Giant Cloud Condensation Nuclei on Drizzle Formation in Stratocumulus: Implications for Cloud Radiative Properties, J. Atmos. Sci., 56, 4100-4117, doi:10.1175/1520-0469(1999)056<4100:TIOGCC>2.0.CO;2, 1999.

Freud, E. and Rosenfeld, D.: Linear relation between convective cloud drop number concentration and depth for rain initiation, J. Geophys. Res.-Atmos., 117, D02207, doi:10.1029/2011JD016457, 2012.

Garratt, J. R.: The atmospheric boundary layer, Cambridge Univ. Press, Cambridge, 1992.

Gerber, H.: Microphysics of marine stratocumulus clouds with two drizzle modes, J. Atmos. Sci., 53, 1649-1662, doi:10.1175/152025 0469(1996)053<1649:MOMSCW>2.0.CO;2, 1996.

Ginis, I., Khain, A. P., and Morozovsky, E.: Effects of Large Eddies on the Structure of the Marine Boundary Layer under Strong Wind Conditions, J. Atmos. Sci., 61, 3049-3064, doi:10.1175/JAS-3342.1, 2004.

Katzwinkel, J., Siebert, H., and Shaw, R. A.: Observation of a Self-Limiting, Shear-Induced Turbulent Inversion Layer Above Marine Stratocumulus, Bound.-Lay. Meteorol., 145, 131-143, doi:10.1007/s10546-011-9683-4, 2011.

Khain, A., Prabha, T. V., Benmoshe, N., Pandithurai, G., and Ovchinnikov, M.: The mechanism of first raindrops formation in deep convective clouds, J. Geophys. Res.-Atmos., 118, 91239140, doi:10.1002/jgrd.50641, 2013.

Khairoutdinov, M. and Kogan, Y.: A New Cloud Physics Parameterization in a Large-Eddy Simulation Model of Marine Stratocumulus, Mon. Weather Rev., 128, 229-243, doi:10.1175/15200493(2000)128<0229:ANCPPI>2.0.CO;2, 2000.

Khairoutdinov, M. F. and Kogan, Y. L.: A large eddy simulation model with explicit microphysics: Validation against aircraft observations of a stratocumulus-topped boundary layer, J. Atmos. Sci., 56, 2115-2131, doi:10.1175/15200469(1999)056<2115:ALESMW>2.0.CO;2, 1999.

Khvorostyanov, V. I.: Mesoscale processes of cloud formation, cloud-radiation interaction, and their modelling with explicit cloud microphysics, Atmos. Res., 39, 1-67, doi:10.1016/01698095(95)00012-G, 1995.

Khvorostyanov, V. I., Curry, J. A., Gultepe, I., and Strawbridge, K.: A springtime cloud over the Beaufort Sea polynya: Threedimensional simulation with explicit spectral microphysics and comparison with observations, J. Geophys. Res., 108, 4296 D9, doi:10.1029/2001JD001489, 2003.

Korolev, A. V., Pinsky, M., and Khain, A.: A New Mechanism of Droplet Size Spectra Broadening During Diffusional Growth, J. Atmos. Sci., 70, 2051-2071, doi:10.1175/JAS-D-12-0182.1, 2013.

Kostinski, A. B.: Drizzle rates versus cloud depths for marine stratocumuli, Environ. Res. Lett., 3, 045019, doi:10.1088/17489326/3/4/045019, 2008.
Kovetz, A. and Olund, B.: The Effect of Coalescence and Condensation on Rain Formation in a Cloud of Finite Vertical Extent, ST - The Effect of Coalescence and Cond, J. Atmos. Sci., 26, 1060-1065, doi:10.1175/15200469(1969)026<1060:TEOCAC>2.0.CO;2, 1969.

Lasher-Trapp, S. G., Cooper, W. A., and Blyth, A. M.: Broadening of droplet size distributions from entrainment and mixing in a cumulus cloud, Q. J. R. Meteorol. Soc., 131, 195-220, 2005.

Lothon, M., Lenschow, D. H., Leon, D., and Vali, G.: Turbulence measurements in marine stratocumulus with airborne Doppler radar, Q. J. R. Meteorol. Soc., 131, 2063-2080, doi:10.1256/qj.04.131, 2005.

Magaritz, L., Pinsky, M., Krasnov, O., and Khain, a.: Investigation of Droplet Size Distributions and Drizzle Formation Using A New Trajectory Ensemble Model, Part II: Lucky Parcels, J. Atmos. Sci., 66, 781-805, doi:10.1175/2008JAS2789.1, 2009.

Magaritz, L., Pinsky, M., and Khain, A.: Effects of stratocumulus clouds on aerosols in the maritime boundary layer, Atmos. Res., 97, 498-512, doi:10.1016/j.atmosres.2010.06.010, 2010.

Magaritz-Ronen, L., Pinsky, M., and Khain, A. P.: Effects of turbulent mixing on the structure and macroscopic properties of stratocumulus clouds demonstrated by a Lagrangian trajectory model, J. Atmos. Sci., 71, 1843-1862, doi:10.1175/JAS-D-120339.1, 2014.

Monin, A. S. and Yaglom, A. M.: Statistical fluid mechanics: mechanics of turbulence, MIT Press, 886 pp., 1975.

Nakajima, T. and King, M. D.: Determination of the optical Thickness and Effective Particle radius of clouds from reflected solar radiation measurment - Part 1: Theory, J. Atmos. Sci., 47, 18781893, 1990.

Pawlowska, H. and Brenguier, J.-L. L.: An observational study of drizzle formation in stratocumulus clouds for general circulation model (GCM) parameterizations, J. Geophys. Res., 108, doi:10.1029/2002JD002679, 2003.

Pinsky, M., Khain, A., and Shapiro, M.: Collision Efficiency of Drops in a Wide Range of Reynolds Numbers: Effects of Pressure on Spectrum Evolution, J. Atmos. Sci., 58, 742-764, doi:10.1175/1520-0469(2001)058<0742:CEODIA >2.0.CO;2, 2001.

Pinsky, M., Magaritz, L., Khain, A., Krasnov, O., and Sterkin, A.: Investigation of Droplet Size Distributions and Drizzle Formation Using a New Trajectory Ensemble Model, Part I: Model Description and First Results in a Nonmixing Limit, J. Atmos. Sci., 65, 2064-2086, doi:10.1175/2007JAS2486.1, 2008.

Pinsky, M., Khain, A., and Magaritz, L.: Representing turbulent mixing of non-conservative values in Eulerian and Lagrangian cloud models, Q. J. R. Meteorol. Soc., 136, 1228-1242, doi:10.1002/qj.624, 2010.

Pinsky, M., Mazin, I. P., Korolev, A., and Khain, A.: Supersaturation and Diffusional Droplet Growth in Liquid Clouds, J. Atmos. Sci., 70, 2778-2793, doi:10.1175/JAS-D-12-077.1, 2013.

Pinsky, M. B. and Khain, A. P.: Effects of in-cloud nucleation and turbulence on droplet spectrum formation in cumulus clouds, Q. J. R. Meteorol. Soc., 128, 501-533, doi:10.1256/003590002321042072, 2002.

Pruppacher, H. R. and Klett, J. D. E. T.-2-nd: Microphysics of Clouds and Precipitation, Oxford Press, 954 pp., 1997.

Randall, D., Krueger, S., Bretherton, C., Curry, J., Duynkerke, P., Moncrieff, M., Ryan, B., Starr, D., Miller, M., Rossow, W., Tse- 
lioudis, G. and Wielicki, B.: Confronting Models with Data: The GEWEX Cloud Systems Study, B. Am. Meteorol. Soc., 84, 455469, doi:10.1175/BAMS-84-4-455, 2003.

Rosenfeld, D., Kaufman, Y. J., and Koren, I.: Switching cloud cover and dynamical regimes from open to closed Benard cells in response to the suppression of precipitation by aerosols, Atmos. Chem. Phys., 6, 2503-2511, doi:10.5194/acp-6-2503-2006, 2006.

Rosenfeld, D., Wang, H., and Rasch, P. J.: The roles of cloud drop effective radius and LWP in determining rain properties in marine stratocumulus, Geophys. Res. Lett., 39, L13801, doi:10.1029/2012GL052028, 2012.

Siebert, H., Shaw, R. A., and Warhaft, Z.: Statistics of SmallScale Velocity Fluctuations and Internal Intermittency in Marine Stratocumulus Clouds, J. Atmos. Sci., 67, 262-273, doi:10.1175/2009JAS3200.1, 2010.

Smith, S. D.: Coefficients for sea surface wind stress, heat flux, and wind profiles as a function of wind speed and temperature, J. Geophys. Res., 93, 15467-15472, doi:10.1029/JC093iC12p15467, 1988.

Stevens, B., Lenschow, D. H., Vali, G., Gerber, H., Bandy, A., Blomquist, B., Brenguier, J.-L., Bretherton, C. S., Burnet, F., Campos, T., Chai, S., Faloona, I., Friesen, D., Haimov, S., Laursen, K., Lilly, D. K., Loehrer, S. M., Malinowski, S. P., Morley, B., Petters, M. D., Rogers, D. C., Russell, L., SavicJovcic, V., Snider, J. R., Straub, D., Szumowski, M. J., Takagi, H., Thornton, D. C., Tschudi, M., Twohy, C., Wetzel, M., and Van Zanten, M. C.: Dynamics and chemistry of marine stratocumulus-DYCOMS-II, B. Am. Meteorol. Soc., 84, 579593, doi:10.1175/BAMS-84-5-579, 2003a.
Stevens, B., Lenschow, D. H., Faloona, I., Moeng, C.-H., Lilly, D. K., Blomquist, B., Vali, G., Bandy, A., Campos, T., Gerber, H., Haimov, S., Morley, B., and Thornton, D.: On entrainment rates in nocturnal marine stratocumulus, Q. J. R. Meteorol. Soc., 129, 3469-3493, doi:10.1256/qj.02.202, 2003b.

Stevens, B., Moeng, C.-H. H., Ackerman, A. S., Bretherton, C. S., Chlond, A., de Roode, S., Edwards, J., Golaz, J.-C. C., Jiang, H. L., Khairoutdinov, M., Kirkpatrick, M. P., Lewellen, D. C., Lock, A., Müller, F., Stevens, D. E., Whelan, E., Zhu, P., and Muller, F.: Evaluation of Large-Eddy Simulations via Observations of Nocturnal Marine Stratocumulus, Mon. Weather Rev., 133, 1443-1462, doi:10.1175/MWR2930.1, 2005.

Van Zanten, M. C. M. C., Stevens, B., Vali, G., and Lenschow, D. H.: Observations of drizzle in nocturnal marine stratocumulus, J. Atmos. Sci., 62, 88-106, 2005. 